\title{
A Review of Insulin Resistance in Type 1 Diabetes: Is There a Place for Adjunctive Metformin?
}

Gagan Priya (D) Sanjay Kalra

Received: October 2, 2017 / Published online: November 14, 2017

(C) The Author(s) 2017. This article is an open access publication

\section{ABSTRACT}

There is a rising trend of overweight and obesity among individuals with type 1 diabetes. This is often associated with insulin resistance, increased insulin dose requirements and poor glycemic control. Insulin resistance is also seen during puberty and is strongly related to increased risk of cardiovascular disease. The role of metformin as an adjunct to ongoing intensive insulin therapy in type 1 diabetics has been evaluated in several randomized trials, including the recently concluded T1D Exchange Network trial in adolescents and the REMOVAL trial in adults. Metformin reduces the insulin dose requirement, insulin-induced weight gain, and total and LDL cholesterol, but results in an increased risk of gastrointestinal adverse effects and a minor increase in the risk of hypoglycemia. In addition, metformin has been shown to reduce maximal carotid intima media thickness and therefore may extend cardioprotective benefits in type 1 diabetes. The role of metformin as adjunctive therapy in type 1

Enhanced content To view enhanced content for this article go to http://www.medengine.com/Redeem/ 6ECCF06025FC31C4.

\section{G. Priya $(\square)$}

Fortis Hospital, Mohali, India

e-mail: gagan.priya@fortishealthcare.com

S. Kalra

Bharti Hospital, Karnal, India diabetes needs to be explored further in outcome trials.

Keywords: Type 1 diabetes; Overweight and obesity; Insulin resistance; Adjunctive therapy; Metformin

\section{INTRODUCTION}

Type 1 diabetes (T1D) results from an autoimmune destruction of pancreatic $\beta$-cells, and the predominant pathophysiology is an almost absolute insulinopenia. Therefore, injectable insulin is the cornerstone of treatment, and advances in insulin therapy have led to an increase in life expectancy of T1D individuals. While there have been significant advances in the development of newer insulin analogs with more physiological pharmacokinetic profiles, continuous subcutaneous insulin infusion (CSII) and continuous glucose monitoring, attainment and maintenance of glycemic goals remain formidable challenges in T1D.

Insulin resistance has also been described in T1D and may be a potential target for intervention in addition to insulin therapy. The disease is also characterized by increased glucagon secretion in the postprandial period, and targeting such aberrant glucagon secretion may be another useful adjunctive strategy [1]. In Table 1, we list the limitations of insulin 
Table 1 Limitations of injectable insulin and role of adjunctive non-insulin antidiabetic therapies in type 1 diabetes

\begin{tabular}{ll}
\hline Limitations of injectable insulin therapy & $\begin{array}{l}\text { Potential role of adjunctive non-insulin } \\
\text { antidiabetics }\end{array}$ \\
\hline $\begin{array}{l}\text { Pharmacodynamic profiles of available insulins do not completely mimic } \\
\text { physiological needs }\end{array}$ & $\begin{array}{l}\text { Improve glycemic control } \\
\text { Target glucagon dysregulation }\end{array}$ \\
Risk of iatrogenic hypoglycemia & Reduce glycemic variability \\
Insulin-induced weight gain & Reduce postprandial glycemic excursions \\
Poor patient adherence & Target insulin resistance \\
Unable to address glucagon dysfunction & Reduce insulin dose requirement \\
Psychological stress & Reduce insulin-induced weight gain \\
& Lipid management \\
& Reduce risk of microvascular and macrovascular \\
& complications \\
\hline
\end{tabular}

therapy and the potential role of adjunctive non-insulin antidiabetic agents in type 1 diabetes. Pramlintide is approved for use in T1D, and several other anti-diabetic drugs have been investigated for their add-on role, including metformin, thiazolidinediones, DPP4 inhibitors, GLP-1 analogs, $\alpha$-glucosidase inhibitors, SGLT2 inhibitors and dual SGLT1-SGLT2 inhibitors $[2,3]$.

In this review, we discuss the role of insulin resistance in the pathophysiology of type 1 diabetes and the efficacy and safety of metformin as adjunctive therapy to insulin in type 1 diabetic individuals. This article is based on previously conducted studies and does not involve any new studies of human or animal subjects performed.

\section{RISING PREVALENCE OF OVERWEIGHT AND OBESITY IN TYPE 1 DIABETES}

While the traditional view remains that type 1 diabetics are lean with normal body weight, the prevalence of overweight and obesity in type 1 diabetic individuals is increasing in parallel with the global population trends in weight gain [4]. Libman et al. reported that the prevalence of overweight and obesity at onset of insulin-dependent diabetes among children almost tripled from $12.6 \%$ to $36.8 \%$ between the time periods of 1979-1989 and 1990-1998, following the general population trend [5]. In several cohorts, the prevalence of overweight and obesity in T1D children was reported to be higher than in the normal population, with an estimated $22.1 \%$ of T1D children being overweight or obese in the US SEARCH for Diabetes in Youth study cohort [6]. The median BMI was greater than the national reference values in the T1D Exchange (US, $n=11,435)$ and Diabetes Prospective Follow-up (Europe, $n=21,501$ ) registries (age 1-18 years), particularly in the US population [7].

Excess weight gain in children was suggested to be an "accelerating factor" [8] for development of T1D in the Pittsburgh cohort [5] and in another study from Finland [9]. A 10\% increment in weight was associated with a $50-60 \%$ increase in risk of T1D before the age of 3 years and a $20-40 \%$ increase from the age of $3-$ 10 years. Obesity after 3 years of age was associated with a two-fold risk of developing T1D [9]. There was also an inverse relation between age at diagnosis and BMI. It has been suggested that insulin resistance associated with childhood obesity increases the demand on $\beta$-cells, 
increases antigen presentation and accelerates autoimmune damage.

Overweight and obesity may further increase during the individual's lifetime, related to intensive insulin therapy and over-insulinization, recurrent hypoglycemia and defensive snacking [10]. In the DCCT trial, individuals in the intensive arm had a 33\% increased risk of being overweight, and the mean weight gain was $4.6 \mathrm{~kg}$ more than in the conventional arm [11]. In the Pittsburgh Epidemiology of Diabetes Complications Study cohort of 589 type 1 diabetics, temporal patterns of weight were assessed for 18 years. At baseline, 28.6\% individuals were overweight and $3.4 \%$ obese. The prevalence of overweight increased by $47 \%$ and prevalence of obesity increased sevenfold over 18 years [12].

\section{INSULIN RESISTANCE IN TYPE 1 DIABETES}

There are obvious technical difficulties in estimating insulin sensitivity in individuals with T1D using traditional methods, and the hyperinsulinemic euglycemic clamp remains the gold standard [13]. Insulin resistance is often observed in type 1 diabetics during pubertal development and inter-current illness. Puberty is associated with a physiological impairment of insulin sensitivity, related to the surge in growth hormone and sex steroids, especially during the later stages of pubertal development. Puberty-related insulin resistance mainly affects peripheral glucose utilization, with less effect on fat metabolism [14]. However, insulin resistance may be more common in T1D and was demonstrated as early as 1982 by DeFronzo et al. [15]. Poor glycemic control in type 1 diabetics is associated with hepatic insulin resistance, while whole-body glucose utilization was reported to be lower even in those who were well controlled $[13,14]$.

Insulin resistance may be related to obesity, sedentary lifestyle, family history of type 2 diabetes and weight gain associated with intensive insulin therapy. Table 2 enumerates the factors causing increased risk of insulin resistance in T1D. The term 'double diabetes,' coined in
2001, describes individuals who have T1D autoantibody positivity but develop significant insulin resistance $[13,16]$. They have lower frequency of high-risk MHC alleles and greater association with genes contributing to risk of type 2 diabetes. These individuals may be at high risk of metabolic dysfunction including hypertension, dyslipidemia and polycystic ovary syndrome.

Some groups have reported that type 1 diabetic youth with insulin resistance do not have the typical phenotype of central adiposity, hepatic steatosis, low HDL or low adiponectin and have predominant peripheral insulin resistance with less hepatic involvement [17]. However, several other groups have shown an increased prevalence of cardiovascular risk factors including hypertension, dyslipidemia and metabolic syndrome in type 1 diabetics. In the Dutch cohort of 283 children with T1D (median age 12.8 years), $38.5 \%$ were overweight or obese. Compared to normal-weight children, they had a higher prevalence of hypertension $(23.9 \%$ vs. $5.7 \%)$, metabolic syndrome $(25.7 \%$ vs. $6.3 \%)$ and hypertransaminasemia ( $15.6 \%$ vs. $4.5 \%$ ) [18]. Patients in the highest quartile of weight gain (mean BMI $31 \mathrm{~kg} / \mathrm{m}^{2}$ ) in the DCCT/ EDIC trial had increased prevalence of central obesity, insulin resistance, dyslipidemia, blood pressure and more extensive atherosclerosis [11].

Insulin resistance has been proposed as one of the reasons for suboptimal glycemic control in T1D, associated with increased insulin dose requirements and further weight gain. Weight gain may create concerns about body image, especially in teenagers and females, and affect adherence to treatment. Hence, prevention of weight gain and long-term weight management should be considered in the treatment plan, and strategies to counter insulin resistance and prevent macrovascular disease are often needed. However, there is a need to better understand the role played by insulin resistance in the pathophysiology of T1D and to evaluate whether addressing insulin resistance would result in improved outcomes. 
Table 2 Factors causing insulin resistance in type 1 diabetes

\begin{tabular}{|c|c|}
\hline \multicolumn{2}{|c|}{ Factors causing insulin resistance in type 1 diabetes } \\
\hline \multirow[t]{4}{*}{ Genetic/familial } & Overweight or obesity \\
\hline & Family history of type 2 diabetes \\
\hline & High risk ethnic group \\
\hline & Double diabetes \\
\hline \multirow[t]{2}{*}{ Physiological } & Puberty and adolescence \\
\hline & Increasing age \\
\hline \multirow[t]{5}{*}{ Treatment related } & Uncontrolled glycemia - chronic hyperglycemia/glucotoxicity \\
\hline & Intensive insulin therapy and weight gain \\
\hline & Hypoglycemia and defensive snacking \\
\hline & Overinsulinization with resultant iatrogenic peripheral hyperinsulinemia \\
\hline & $\begin{array}{l}\text { Mismatch between physiological insulin profile needs and pharmadynamic profiles of available } \\
\text { insulins }\end{array}$ \\
\hline \multirow{2}{*}{$\begin{array}{l}\text { Lifestyle and } \\
\text { psychological }\end{array}$} & Sedentary lifestyle \\
\hline & Eating disorders/bulimia \\
\hline \multirow[t]{2}{*}{ Others } & Drugs \\
\hline & Intercurrent illness \\
\hline
\end{tabular}

\section{INCREASED CARDIOVASCULAR RISK: RELATION WITH INSULIN RESISTANCE}

There is a significantly high risk of cardiovascular disease in T1D, which is often attributed to hyperglycemia. Cardiovascular disease is the leading cause of death, with the life expectancy of adults aged 20 years with T1D reduced by 13 years [19]. Vascular dysfunction and increased carotid intima media thickness are evident as early as childhood and adolescence, within a few years since onset of diabetes [10]. The process is accelerated by insulin resistance, weight gain and obesity.

Indeed, insulin resistance may have a greater role in the development of cardiovascular disease in type 1 diabetics than the level of glycemic control. Reduced insulin sensitivity in adolescents was associated with increased risk of cardiovascular $(\mathrm{CV})$ risk factors such as elevated waist circumference, blood pressure, cholesterol and C-reactive protein in the Determinants of Macrovascular Disease in Adolescents with T1DM study [20]. Insulin resistance in T1D adolescents has been associated with reduced cardiopulmonary fitness, as measured by peak oxygen consumption and oxygen uptake kinetics, diastolic dysfunction and left ventricular hypertrophy [17]. In a prospective cohort of 603 type 1 diabetics in the Pittsburgh Epidemiology of Diabetes Complications (EDC) study, insulin resistance but not $\mathrm{HbA1c}$ predicted coronary artery disease end points [21]. Similarly, insulin resistance was a more significant determinant of coronary artery calcifications than hyperglycemia in the Coronary Artery Calcification in Type 1 Diabetes study [22]. This suggests that insulin resistance may be an important therapeutic target for reducing $\mathrm{CV}$ risk in T1D. 


\section{THE RATIONALE FOR USE OF METFORMIN IN TYPE 1 DIABETES}

Metformin inhibits complex 1 of the mitochondrial respiratory chain and alters the cellular energy state by triggering activation of AMP-activated protein kinase (AMPK) in liver and skeletal muscle, a nutrient sensor that is activated in states of low energy balance [23]. The predominant effect is reduced hepatic gluconeogenesis and hepatic glucose output, but there is also an increase in insulin-stimulated peripheral glucose uptake, especially in skeletal muscle. Metformin decreases intestinal glucose absorption and increases intestinal secretion of GLP-1, further contributing to its glucose-lowering effect [23]. An alteration in the composition of intestinal microbiota has also been suggested. In addition, metformin has pleiotropic effects mediated via AMP-activated kinase, leading to decreased fatty acid oxidation and lipid lowering, inhibition of the proinflammatory pathway in perivascular adipose tissue, inhibition of STAT3 and monocyte-to-macrophage differentiation in vascular tissue and improved endothelial function. Metformin also inhibits AGE formation by binding and inactivating methylglyoxal via an AMPK-independent pathway, which may further contribute to its cardioprotective effects [19].

In type 2 diabetes, metformin use is associated with a reduction in fasting plasma glucose, HbA1c, LDL cholesterol, serum triglycerides, VLDL cholesterol and C-reactive protein. There is a mild reduction in weight or a weight neutral effect. When used as an add-on to insulin therapy in type 2 diabetes, metformin can improve glycemic control, reduce insulin dose requirements, limit insulin-induced weight gain and improve complication risk. It has demonstrated a definite cardioprotective effect in type 2 diabetes. Metformin has a good safety profile and is generally well tolerated.

Hence, there has been a growing interest in exploring the role of metformin as an adjunct to injectable insulin therapy in T1D, with the aim of improving insulin sensitivity and glycemic control, limiting the insulin dose and weight gain and the long-term possibility of $\mathrm{CV}$ risk reduction. In 1985, Gin et al. demonstrated that metformin resulted in 18\% improvement in insulin sensitivity measured by euglycemic hyperinsulinemic clamp in ten type 1 diabetic patients with normal weight [24]. Similar results were shown by Moon et al. more recently in 2007 [25]. Early pilot studies in adolescents and adults suggested that metformin could be used as an adjunct to insulin with reductions in HbA1c, insulin dose, BMI and lipids [25-28].

\section{CLINICAL TRIAL EVIDENCE OF METFORMIN IN ADULTS WITH TYPE 1 DIABETES}

Initial small uncontrolled studies of metformin in type 1 diabetics reported a reduction in insulin dose by almost $25 \%$ and a modest reduction in weight, with a variable effect on glycemia and lipids [25, 28-30]. Metformin was compared to placebo as an adjunct to CSII in 62 T1D patients and resulted in a significant reduction in the total daily insulin dose, basal insulin dose, total and LDL cholesterol after 6 months. There was no change in HbA1c or risk of hypoglycemia, but there was an increased incidence of gastrointestinal side effects [31]. Lund et al. [32] evaluated the effect of metformin versus placebo in 100 patients and found no improvement in HbA1c over 1 year. There was, however, a sustained reduction in weight and insulin dose. Forty percent of participants reported gastrointestinal side effects, but very few discontinued treatment. Hypoglycemia incidence, including severe hypoglycemia, was greater with metformin than placebo [32]. In their meta-analysis of five trials, Pang and Narendran (2008) reported a small but significant reduction in HbA1c $(-0.27 \%)$, moderate reduction in insulin dose and improvement in total cholesterol, but no benefit in weight with metformin in type 1 diabetics who had $\mathrm{BMI} \geq 25 \mathrm{~kg} / \mathrm{m}^{2}$ or had insulin resistance (insulin dose $>0.9 \mathrm{U} / \mathrm{kg}$ ) [33].

The systematic review of nine trials by Vella et al. [34] found a decrease in insulin dose (5.7-10.1 U/day in 6 of 7 studies), HbA1c 
(0.6-0.9\% in 4 of 7 studies), weight (1.7-6 $\mathrm{kg}$ in 3 of 6 studies) and total cholesterol (0.3-$0.41 \mathrm{mmol} / \mathrm{l}$ in 3 of 7 studies). In the five randomized, double-blind trials that had adequate data for combined effect estimates, metformin use in adolescents and adults resulted in a significant reduction in insulin dose requirements (6.6 U/day, $p<0.001)$ and weight reduction in some trials, but no consistent evidence for HbA1c reduction (absolute reduction $0.11 \%$, $p$ 0.42). Metformin was well tolerated, gastrointestinal side effects were minimal, and there was a slight increased trend towards hypoglycemia [34].

A recent meta-analysis (2015) by Liu et al. included eight trials of metformin versus placebo including 300 patients. Use of metformin was associated with a reduction in weight (mean difference $-2.41,95 \%$ CI -4.17 to $-0.65, p 0.007)$, total daily insulin dose (mean difference $-1.36,95 \%$ CI -2.28 to -0.45 , $p$ 0.004) and lipids (reduced total and LDL cholesterol). There was an increased risk of gastrointestinal adverse effects but no increased risk of hypoglycemia or ketoacidosis. There was no effect on HbA1c, fasting plasma glucose or triglycerides [35].

Staels et al. (2017) identified 181 metformin users among 1986 type 1 diabetic patients in a retrospective real-world data from a hospital in Belgium. Those prescribed metformin had higher BMI and higher HbA1c at baseline. There was a downward trend in BMI in initial years after metformin initiation, but the difference in BMI from the control group was lost over 10 years. Metformin was not associated with any long-term beneficial effect on BMI, HbA1c or insulin dose [36].

REMOVAL (2017) was the largest multicenter, double-blind, placebo-controlled trial funded by JDRF assessing the effect of metformin over 3 years in 428 adults (age $\geq 40$ years) with T1D and three or more cardiovascular risk factors [37]. Metformin resulted in a small transient improvement in $\mathrm{HbA} 1 \mathrm{c}$ in the first 6 months. HbA1c was reduced by metformin over 3 years $(-0.13 \%, 95 \%$ CI -0.22 to -0.04 , $p$ 0.006), but this was primarily accounted for by a reduction at 3 months $(-0.24 \%, 95 \%$ CI -0.34 to $-0.13, p<0.0001)$. The difference in
HbA1c between metformin and placebo was not significant at 3 years. There was little difference in insulin dose between the treatment groups at 6 months, but thereafter, the metformin group showed a small albeit sustained reduction in insulin dose in post hoc analysis $(-0.023 \mathrm{U} / \mathrm{kg}$, $95 \%$ CI -0.045 to -0.0005 , p 0.045 , approximately 2 U/day from 6 months onwards). Reduction in body weight was significant with metformin compared to placebo (mean within-person change between the two groups was $-1.17 \mathrm{~kg}, \quad 95 \%$ CI -1.66 to -0.69 , $p<0.0001)$. Reduction in LDL cholesterol was also significant $(-0.13 \mathrm{mmol} / \mathrm{l}, 95 \% \mathrm{CI}-0.24$ to $-0.03, p$ 0.0117) despite a high prevalence of background statin use. An unexpected acute rise in eGFR (by $4 \mathrm{ml} / \mathrm{min} / 1.73 \mathrm{~m}^{2}$ ) occurred on initiation of metformin. The risk of hypoglycemia or ketoacidosis was not increased, but gastrointestinal adverse effects were more common. The discontinuation rate due to gastrointestinal intolerance was twice that of placebo ( $27 \%$ vs. $12 \%)$, and a greater percentage of patients had vitamin B12 deficiency (12\% vs. $5 \%$ over 3 years). Vitamin B12 deficiency may be particularly important in $\mathrm{T} 1 \mathrm{D}$, where there may be associated risk factors such as celiac disease, pernicious anemia or gastroparesis. Thus, REMOVAL demonstrated a favorable effect of metformin on body weight, insulin dose requirement and lipids, similar to previous meta-analyses of smaller studies [34, 35].

There is increased prevalence of polycystic ovary syndrome and hyperandrogenism in women with T1D [38, 39], though the phenotype is milder than seen in relation with type 2 diabetes [40]. In a 9-month randomized controlled trial, Codner et al. examined the effect of metformin in 24 type 1 diabetic females. There was a significant decrease in testosterone, free androgen index, androstenedione, 17- $\alpha$ hydroxyprogesterone and estradiol levels. Moderate to severe acne was reduced from 23.1 to $7.7 \%$, but there was no improvement seen in the hirsutism score or ovulation rates. There was no difference in the HbA1c or insulin dose [41]. 


\section{CLINICAL TRIAL EVIDENCE OF METFORMIN IN ADOLESCENTS WITH TYPE 1 DIABETES}

Peri-pubertal insulin resistance is associated with increased insulin dose requirement, weight gain and poor glycemic control. Non-adherence and behavioral issues may further worsen the control. In DCCT, the average HbA1c achieved by adolescents was 1\% higher than in adults in both intensive and conventional arms, despite a greater insulin requirement $(\mathrm{U} / \mathrm{kg})$ and weight gain [42]. Therefore, insulin sensitizers have long been considered adjunctive therapy to insulin during the peri-pubertal period.

The earliest report of the use of metformin in children was in 1961 by Ferguson et al. in ten children with brittle diabetes [43]. Schatz et al., in 1973, demonstrated that metformin use led to a reduction of the insulin dose in 43 children and adolescents with juvenile diabetes [44]. Early small studies of 3-month duration reported variable effects of metformin. Some studies reported improvements in insulin sensitivity, a reduction in HbA1c, lower total daily insulin dose, BMI and serum lipids, but there was a slightly increased risk of hypoglycemia [26, 45-47]. In an open-label study including 29 type 1 diabetic patients $>10$ years age, addition of metformin led to a significant reduction in insulin dose and HbA1c at 12 months. Serum lipids were decreased but the weight and BMI increased [46]. A 2009 Cochrane review of two randomized studies found a reduction in $\mathrm{HbA} 1 \mathrm{c}$ over 3 months and some reduction in insulin dose, but both trials were short term and had a small number of patients [48].

HbA1c was reduced by $-0.39 \%$ in 28 overweight type 1 diabetic youth over a follow-up of 9 months, along with non-significant reductions in fasting plasma glucose and insulin dose in a randomized, double-blind, placebo-controlled trial [49]. Nadeau et al. reported significant reductions in BMI $Z$-score, waist circumference and insulin dose with low-dose metformin (500-1000 mg per day) in another RCT including 74 pubertal T1D adolescents. Metformin was well tolerated with no increased risk of hypoglycemia, ketoacidosis or severe gastrointestinal symptoms [50]. A recent randomized, placebo-controlled trial from India, including 19 adolescents with poor glycemic control (HbA1c $>9 \%)$ and high insulin dose requirement $(>1.2 \mathrm{U} / \mathrm{kg})$, reported robust benefits. At 6 months, HbA1c was lower by $1.2 \%$ $(p<0.001)$, and this HbA1c reduction was achieved at a lower daily insulin dose (metformin $-0.21 \pm 0.2 \mathrm{U}$ from baseline, placebo $0.05 \pm 0.1 \mathrm{U} / \mathrm{kg} /$ day from baseline, $p<0.001$ ). Use of metformin was, however, associated with more frequent hypoglycemia [51].

In the meta-analysis of 6 randomized trials, including 325 patients in the 6-19-year age group, Al Khalifah et al. found no effect of metformin on HbA1c, but there was a significant improvement in BMI compared to placebo (mean difference $-1.46,95 \%$ CI -2.54 to $-0.38, p<0.01)$ and a modest reduction in insulin dose (mean difference $-0.15 \mathrm{U} / \mathrm{kg}, 95 \%$ CI -0.24 to $-0.06, p<0.01)$ [52]. A recent prospective analysis of a large diabetes registry of children with T1D from Germany and Austria reported similar findings. Konrad et al. identified 525 patients using metformin with insulin and 57,487 patients using insulin alone. Patients prescribed metformin were older (mean age 16.1 years versus 15.2 years), mostly females, had higher BMI-SDS $(+2.03$ vs. +0.51$)$ and higher HbA1c (9.0\% vs. 8.6\%). Hypertension and dyslipidemia were more prevalent, and patients had a higher insulin dose $(0.98 \mathrm{U} / \mathrm{kg}$ vs. $0.93 \mathrm{U} / \mathrm{kg}$ ). Two hundred eighty-five patients on metformin were followed longitudinally (average 1.4 years), and there was a slight reduction in BMI-SDS $[-0.01(-2.01$ to +1.40$)]$ and insulin dose, but there was no improvement in HbA1c [53].

Type 1 Diabetes (T1D) Exchange study was the largest multicenter, double-blind, placebo-controlled randomized controlled trial conducted by JDRF to compare the effect of metformin and placebo as add-on to insulin in 140 overweight and obese adolescents with poor glycemic control (HbA1c 8.8\%) and high insulin dose requirements $(1.1 \mathrm{U} / \mathrm{kg})$ [54]. Initial reduction in $\mathrm{HbA} 1 \mathrm{c}(-0.3 \%$ at 3 months) was not sustained at 6 months. There was a $25 \%$ reduction in insulin dose in $23 \%$ participants 
(compared with $1 \%$ in the placebo group) and $>10 \%$ reduction in BMI in $24 \%$ of those taking metformin (compared with $7 \%$ in nthe placebo group). There was no change in lipid levels. Mild gastrointestinal adverse effects were reported with metformin. Hence, the study did not support the use of metformin in overweight adolescents to improve glycemic control.

\section{DOES METFORMIN HAVE A CARDIOPROTECTIVE EFFECT IN TYPE 1 DIABETES?}

Metformin has an established cardioprotective effect in type 2 diabetes and a similar role in T1D has been the subject of recent research. Use of metformin in T1D is associated with a reduction in several cardiovascular risk factors, including BMI, waist circumference, HbA1c, LDL cholesterol and total cholesterol. In a pilot study including 33 obese type 1 diabetic individuals, Burchardt et al. demonstrated that the addition of metformin resulted in a significant reduction in $\mathrm{HbA1c}$, triglycerides, glycated LDL and BMI [55]. In 100 type 1 diabetics randomized to metformin and placebo, Lund et al. demonstrated a significant reduction in total and LDL cholesterol $(-0.3 \mathrm{mmol} / \mathrm{l})$ with metformin, which remained significant even after adjustment for background statin use [56]. In addition, metformin improved endothelial function in type 1 diabetic individuals [57]. Use of metformin was associated with increased circulating endothelial progenitor cells, pro-angiogenic cells and decreased circulating endothelial cells [58].

Small studies have reported improvement in carotid intima media thickness (cIMT), a surrogate marker for atherosclerosis, with the use of metformin in type 1 diabetics [59]. In an open-label randomized trial involving 84 obese type 1 diabetic individuals by Burchardt et al., addition of metformin resulted in improved glycemic control, weight reduction, reduced LDL cholesterol, reduced glycated LDL and a reduction in carotid IMT $(0.6 \pm 0.1 \mathrm{~cm}$ vs. $0.53 \pm 0.1 \mathrm{~cm} ; P=0.002$ ) over 6 months [60]. The primary end point of the REMOVAL trial was the effect of metformin on cIMT over
3 years in adults with T1D who had three or more CV risk factors. More than $80 \%$ of patients were already on statins. There was a sustained reduction in LDL cholesterol even on a background of statin therapy. Both groups showed a progression of mean far wall cIMT, but the difference in mean within-person cIMT slopes between metformin and placebo groups was $-0.005 \mathrm{~mm}$ per year, $95 \% \mathrm{CI}-0.012$ to -0.002 , $p$ 0.167. There was reduced progression of maximal cIMT with metformin, the difference in slope being $-0.013 \mathrm{~mm}$ per year, 95\% CI -0.024 to $-0.003, p 0.0093$ [37]. Thus, the primary outcome of mean far wall cIMT was not reduced, but there was a significant reduction in maximal cIMT, which was a tertiary outcome. Maximal cIMT is regarded as a measure of more advanced stages of atherosclerotic disease including focal thickening and plaque. There was no effect on endothelial function, measured by the reactive hyperemia index or retinopathy. Laboratory data were insufficient to reliably ascertain the microalbuminuria status.

REMOVAL suggests that metformin may have a direct effect on atherosclerosis progression in T1D, even in middle-aged patients with long disease duration, on a background of antihypertensive and statin therapy. This effect is unlikely to be mediated by improved glycemic control. It remains to be seen if these benefits translate into improved clinical outcomes and whether a similar reduction of cIMT occurs in adolescents and young adults who do not have CV risk factors yet.

\section{CURRENT PLACE OF METFORMIN IN TYPE 1 DIABETES}

Metformin is not approved for use in T1D by the US FDA. However, in the data from the T1D Exchange registry from the US, $6 \%$ of patients were identified as metformin users [61]. In another Scottish registry of 1850 type 1 diabetics, $7.9 \%$ with BMI $>27 \mathrm{~kg} / \mathrm{m}^{2}$ and $13 \%$ with $\mathrm{BMI}>30 \mathrm{~kg} / \mathrm{m}^{2}$ were receiving metformin [62]. In its Standards of Care, the ADA notes that 'adding metformin to insulin therapy may reduce insulin requirements and improve 
Table 3 Benefits and risks of adjunctive metformin in type 1 diabetes

Benefits of adjunctive metformin in type 1 diabetes

Improved insulin sensitivity

Reduced insulin dose

Reduction in BMI

Trend towards a reduction in HbAlc

Reduced total and LDL cholesterol

Reduced carotid intima media thickness and possible CV risk

reduction
Risks associated with metformin in type 1 diabetes

Gastrointestinal adverse effects

Vitamin B12 deficiency

Increased risk of hypoglycemia

? Lactic acidosis or ketoacidosis (not established in trials)

Table 4 Possible indications for use of metformin as an adjunct to insulin therapy in type 1 diabetes

\begin{tabular}{ll}
\hline Patient subgroup & Relative indications for use of metformin \\
\hline $\begin{array}{l}\text { Pre-pubertal children } \\
\text { Peri-pubertal adolescents } \\
\text { and adults }\end{array}$ & Not evaluated for use \\
& Double diabetes \\
& Obeatures of insulin resistance: \\
& in adolescents) \\
& Acanthosis nigricans \\
& High insulin dose \\
& High insulin dose requirement (total daily dose $\geq 1 \mathrm{U} / \mathrm{kg} /$ day) \\
& Rapid weight gain with insulin \\
& Polycystic ovary syndrome \\
& Concomitant CV risk factors (central obesity, dyslipidemia, hypertension, family history of \\
& CVD) or established CV disease \\
\hline
\end{tabular}

metabolic control in overweight/obese patients with poorly controlled type 1 diabetes' [63]. In 2015, the UK NICE guidelines recommended use of metformin in adults with type 1 diabetes with $\mathrm{BMI} \geq 25$ or $\mathrm{BMI} \geq 23 \mathrm{~kg} / \mathrm{m}^{2}$ for people of South Asian and related ethnic groups, who want to improve glucose control while minimizing their effective insulin dose [64].

However, there is little evidence to support that it can improve glycemic control in T1D, and the initial transient reduction in $\mathrm{HbA1c}$ is not maintained over time. This could be due to down titration of the insulin dose to avoid hypoglycemia. Thus, there is a need to revise the guidelines and acknowledge that there is no sustained glycemic benefit of adjunctive metformin in T1D and that there is no particular glycemic efficacy in overweight/obese individuals. On the other hand, adjunctive use of metformin in T1D results in significant reductions in the insulin dose requirement and insulin-induced weight gain and may therefore, be particularly useful in overweight/obese type 
1 diabetics. Therefore, overall, metformin has an insulin-sensitizing effect in type 1 diabetics.

Recent evidence suggests that metformin reduces LDL cholesterol and maximal cIMT and may extend cardioprotective benefits in T1D. Metformin use may thus be warranted to improve $\mathrm{CV}$ risk management in T1D and to reduce insulin dose requirements. Further outcome studies are needed to assess whether there is an actual reduction in CV outcomes. Such studies may not be easily forthcoming as they would require many type 1 diabetics to be followed for a long time, and there may be difficulty in funding such trials, unlike in type 2 diabetes. In Tables 3 and 4, we summarize the risks and benefits of adjunctive metformin and enumerate the possible indications for use of metformin as an adjunct to insulin therapy in T1D.

\section{CONCLUSION}

The use of metformin as adjunctive therapy to insulin in type 1 diabetes results in a transient reduction in $\mathrm{HbA1c}$ that is not sustained with long-term use. However, there is a significant reduction in body weight and BMI, insulin dose and lipids. It also reduces the maximal carotid intima media thickness in individuals at high risk of cardiovascular disease. Therefore, the use of metformin as an add-on to intensive insulin therapy can be considered, and the potential for cardiovascular risk reduction should be explored further.

\section{ACKNOWLEDGEMENTS}

No funding or sponsorship was received for the publication of this article. All named authors meet the International Committee of Medical Journal Editors (ICMJE) criteria for authorship for this manuscript, take responsibility for the integrity of the work as a whole and have given final approval for the version to be published.

Disclosures. Gagan Priya and Sanjay Kalra have nothing to disclose.
Compliance with Ethics Guidelines. This article is based on previously conducted studies and does not involve any new studies of human or animal subjects performed.

Open Access. This article is distributed under the terms of the Creative Commons Attribution-NonCommercial 4.0 International License (http://creativecommons.org/licenses/ by-nc/4.0/), which permits any noncommercial use, distribution, and reproduction in any medium, provided you give appropriate credit to the original author(s) and the source, provide a link to the Creative Commons license, and indicate if changes were made.

\section{REFERENCES}

1. Sherr J, Tsalikian E, Fox L, et al. Dysregulation of alpha-cell function in youth during the first 2 years of T1D: recipricol abnormalities in glucagon responses to mixed meal feedings and hypoglycemia. Diabetes. 2012;61(Supplement 1):A52-3.

2. Livingstone R, Boyle JG, Petrie JR. Removal study team. A new perspective on metformin therapy in type 1 diabetes. Diabetologia. 2017; . https://doi. org/10.1007/s00125-017-4364-6.

3. Munir KM, Davis SN. The treatment of type 1 diabetes mellitus with agents approved for type 2 diabetes mellitus. Expert Opin Pharmacother. 2015;16(15):2331-41. https://doi.org/10.1517/ 14656566.2015.1084502.

4. Polsky S, Ellis SL. Obesity, insulin resistance, and type 1 diabetes mellitus. Curr Opin Endocrinol Diabetes Obes. 2015;22:277-82. https://doi.org/10. 1097/MED.0000000000000170.

5. Libman IM, Pietropaolo M, Arslanian SA, LaPorte $\mathrm{RE}$, Becker DJ. Changing prevalence of overweight children and adolescents at onset of insulin-treated diabetes. Diabetes Care. 2003;26(10):2871-5. https://doi.org/10.2337/diacare.26.10.2871.

6. Liu LL, Lawrence JM, Davis C, Liese AD, Pettitt DJ, Pihoker C, Dabelea D, Hamman R, Waitzfelder B, Kahn HS. Prevalence of overweight and obesity in youth with diabetes in USA: the SEARCH for Diabetes in Youth study. Pediatr Diabetes. 2010;11(1):4-11.

7. DuBose SN, Hermann JM, Tamborlane WV, Beck RW, Dost A, DiMeglio LA, Schwab KO, Holl RW, 
Hofer SE, Maahs DM. Type 1 diabetes exchange clinic network and diabetes prospective follow-up registry. Obesity in youth with type 1 diabetes in Germany, Austria, and the United States. J Pediatr. 2015;167(3):627-32.e1-4. https://doi.org/10.1016/j. jpeds.2015.05.046 (Epub 2015 Jul 8).

8. Wilkin TJ. The accelerator hypothesis: weight gain as the missing link between type I and type II diabetes. Diabetologia. 2001;44(7):914-22.

9. Hypponen E, Virtanen SM, Kenward MG, Knip M, Akerblom HK. Childhood Diabetes in Finlad Study Group. Obesity, increased linear growth and risk of type 1 diabetes in children. Diabetes Care. 2000;23(12):1755-60.

10. Klupa T. Metformin in type 1 diabetes mellitus? Revisiting treatment dogmas in diabetes. Pol Arch Med Wewn. 2016;126(7-8):461-2. https://doi.org/ 10.20452/pamw.3533.

11. Purnell JQ, Zinman B, Brunzell JD. DCCT/EDIC Research Group. The effect of excess weight gain with intensive diabetes mellitus treatment on cardiovascular disease risk factors and atherosclerosis in type 1 diabetes mellitus results from the Diabetes Control and Complications Trial/Epidemiology of Diabetes Interventions and Complications Study (DCCT/EDIC) Study. Circulation. 2013;127:180-7.

12. Conway B, Miller RG, Costacou T, Fried L, Kelsey S, Evans RW, Orchard TJ. Temporal patterns in overweight and obesity in type 1 diabetes. Diabet Med. 2010;27(4):398-404. https://doi.org/10.1111/j. 1464-5491.2010.02956.x.

13. Kaul K, Apostolopoulou M, Roden M. Insulin resistance in type 1 diabetes mellitus. Metabolism. 2015;64(12):1629-39. https://doi.org/10.1016/j. metabol.2015.09.002 (Epub 2015 Sep 11).

14. Bacha F, Klinepeter Bartz S. Insulin resistance, role of metformin and other non-insulin therapies in pediatric type 1 diabetes. Pediatric Diabetes. 2016;17:545-58.

15. DeFronzo RA, Hendler R, Simonson D. Insulin resistance is a prominent feature of insulin-dependent diabetes. Diabetes. 1982;31(9):795-801.

16. Minges KE, Whittemore R, Grey M. Overweight and obesity in youth with type 1 diabetes. Annu Rev Nurs Res. 2013;31:47-69. https://doi.org/10.1891/ 0739-6686.31.47.

17. Nadeau KJ, Regensteiner JG, Bauer TA, et al. Insulin resistance in adolescents with type 1 diabetes and its relationship to cardiovascular function. J Clin Endocrinol Metab. 2010;95(2):513-21.
18. Van Vliet M, Van der Heyden JC, Diamant M, Van der Rosenstiel IA, Schindhelm RK, Aanstoot HJ, Veeze HJ. Overweight is highly prevalent in children with type 1 diabetes and associates with cardiometabolic risk. J Pediatr. 2010;156(6):923-9.

19. Livingstone SJ, Levin D, Looker HC, Lindsay RS, Wild SH, Joss N, Leese G, Leslie P, McCrimmon RJ, Metcalfe W, et al. Estimated life expectancy in a Scottish cohort with type 1 diabetes, 2008-2010. JAMA. 2015;313:37-44.

20. Specht BJ, Wadwa RP, Snell-Bergeon JK, Nadeau KJ, Bishop FK, Maahs DM. Estimated insulin sensitivity and cardiovascular disease risk factors in adolescents with and without type 1 diabetes. J Pediatr. 2013;162(2):297-301. https://doi.org/10.1016/j. jpeds.2012.07.036.

21. Orchard TJ, Olson JC, Erbey JR, Williams K, Forrest KY, Smithline Kinder L, Ellis D, Becker DJ. Insulin resistance-related factors, but not glycemia, predict coronary artery disease in type 1 diabetes: 10-year follow-up data from the Pittsburgh Epidemiology of Diabetes Complications Study. Diabetes Care. 2003;26:1374-9.

22. Schauer IE, Snell-Bergeon JK, Bergman BC, et al. Insulin resistance, defective insulin-mediated fatty acid suppression, and coronary artery calcification in subjects with and without type 1 diabetes: the CACTI study. Diabetes. 2011;60:306-14.

23. Thomas I, Gregg B. Metformin; a review of its history and future: from lilac to longevity. Pediatr Diabetes. 2017;18(1):10-6. https://doi.org/10.1111/ pedi. 12473.

24. Gin H, Messerchmitt C, Brottier E, Aubertin J. Metformin improved insulin resistance in type I, insulin-dependent, diabetic patients. Metabolism. 1985;34(10):923-5.

25. Moon RJ, Bascombe LA, Holt RI. The addition of metformin in type 1 diabetes improves insulin sensitivity, diabetic control, body composition and patient well-being. Diabetes Obes Metab. 2007;9(1):143-5.

26. Urakami T, Morimoto S, Owada M, Harada K. Usefulness of the addition of metformin to insulin in pediatric patients with type 1 diabetes mellitus. Pediatr Int. 2005;47(4):430-3. https://doi.org/10. 1111/j.1442-200x.2005.02075.x PMID: 16091082.

27. Gómez R, Mokhashi MH, Rao J, Vargas A, Compton T, McCarter R, Chalew SA. Metformin adjunctive therapy with insulin improves glycemic control in patients with type 1 diabetes mellitus: a pilot study. J Pediatr Endocrinol Metab. 2002;15(8):1147-51. 
28. Khan AS, McLoughney CR, Ahmed AB. The effect of metformin on blood glucose control in overweight patients with type 1 diabetes. Diabet Med. 2006;23(10):1079-84.

29. Pagano G, Tagliaferro V, Carta Q, Caselle MT, Bozzo C, Vitelli F, Trovati M, Cocuzza E. Metformin reduces insulin requirement in type 1 (insulin-dependent) diabetes. Diabetologia. 1983;24(5):351-4.

30. Jacobsen IB, Henriksen JE, Beck-Nielsen H. The effect of metformin in overweight patients with type 1 diabetes and poor metabolic control. Basic Clin Pharmacol Toxicol. 2009;105(3):145-9. https://doi.org/10.1111/j.1742-7843.2009.00380.x Epub 2009 May 26.

31. Meyer L, Böhme P, Delbachian I, Lehert P, Cugnardey N, Drouin P, Guerci B. The benefits of metformin therapy during continuous subcutaneous insulin infusion treatment of type 1 diabetic patients. Diabetes Care. 2002;25:2153-8.

32. Lund SS, Tarnow L, Astrup AS, et al. Effect of adjunct metformin treatment in patients with type-1 diabetes and persistent inadequate glycaemic control: a randomized study. PLoS ONE. 2008;3(10):e3363.

33. Pang TT, Narendran P. Addressing insulin resistance in type 1 diabetes. Diabet Med. 2008;25:1015-24.

34. Vella S, Buetow L, Royle P, Livingstone S, Colhoun HM, Petrie JR. The use of metformin in type 1 diabetes: a systematic review of efficacy. Diabetologia. 2010;53(5):809-20.

35. Liu C, Wu D, Zheng X, et al. Efficacy and safety of metformin for patients with type 1 diabetes mellitus: a meta-analysis. Diabetes Technol Ther. 2015;17:142-8.

36. Staels F, Moyson C, Mathieu C. Metformin as add-on to intensive insulin therapy in type 1 diabetes mellitus. Diabetes Obes Metab. 2017. https:// doi.org/10.1111/dom.12948.

37. Petrie JR, Chaturvedi N, Ford I, Brouwers MCGJ, Greenlaw N, Tillin T, Hramiak I, Hughes AD, Jenkins AJ, Klein BEK, Klein R, Ooi TC, Rossing P, Stehouwer CDA, Sattar N, Colhoun HM, REMOVAL Study Group. Cardiovascular and metabolic effects of metformin in patients with type 1 diabetes (REMOVAL): a double-blind, randomised, placebo-controlled trial. Lancet Diabetes Endocrinol. 2017;5(8):597-609. https://doi.org/10.1016/ S2213-8587(17)30194-8 (Epub 2017 Jun 11).

38. Escobar-Morreale HF, Roldan B, Barrio R, Alonso M, Sancho J, de la Calle H, Garcia-Robles R. High prevalence of the polycystic ovary syndrome and hirsutism in women with type 1 diabetes mellitus. J Clin Endocrinol Metab. 2000;85:4182-7.

39. Codner E, Escobar-Morreale HF. Clinical review: Hyperandrogenism and polycystic ovary syndrome in women with type 1 diabetes mellitus. J Clin Endocrinol Metab. 2007;92:1209-16.

40. Roldan B, Escobar-Morreale HF, Barrio R, de La Calle H, Alonso M, Garcia-Robles R, Sancho J. Identification of the source of androgen excess in hyperandrogenic type 1 diabetic patients. Diabetes Care. 2001;24:1297-9.

41. Codner E, Iniguez G, Lopez P, Mujica V, Eyzaguirre FC, Asenjo S, et al. Metformin for the treatment of hyperandrogenism in adolescents with type 1 diabetes mellitus. Hormone research in paediatrics. 2013;80(5):343-9. https://doi.org/10.1159/000355 513 PMID: 24280743.

42. DCCT Research Group. Effect of intensive diabetes treatment on the development and progression of long term complications in adolescents with insulin-dependent diabetes mellitus. Diabetes Control and Complications Trial. J Pediatrics. 1994;125:177-88.

43. Ferguson AW, De La Harpe PL, Farquhar JW. Dimethyldiguanide in the treatment of diabetic children. Lancet. 1961;1:1367-9.

44. Schatz H, Winkler G, Jonatha EM, Pfeiffer EF. Studies on juvenile-type diabetes in children. Assessment of control under treatment with constant and variable doses of insulin with or without addition of biguanides. Diabete Metab. 1975;1:211-20.

45. Sarnblad S, Kroon M, Aman J. Metformin as additional therapy in adolescents with poorly controlled type 1 diabetes: randomised placebo-controlled trial with aspects on insulin sensitivity. Eur J Endocrinol. 2003;149:323-9.

46. Setoodeh A, Didban A, Rabbani A, Sayarifard A, Abbasi F, Sayarifard F, Hoseinzade F. The effect of metformin as an adjunct therapy in adolescents with type 1 diabetes. J Clin Diagnostic Res. 2017;11(4):SC01-4. https://doi.org/10.7860/JCDR/ 2017/24901.9725.

47. Hamilton J, Cummings E, Zdravkovic V, Finegood D, Daneman D. Metformin as an adjunct therapy in adolescents with type 1 diabetes and insulin resistance: a randomized controlled trial. Diabetes Care. 2003;26(1):138-43 PMID: 12502670.

48. Abdelghaffar S, Attia AM. Metformin added to insulin therapy for type 1 diabetes mellitus in adolescents. Cochrane Database of Systematic 
Reviews. 2009;1:CD006691. https://doi.org/10. 1002/14651858.CD006691.pub2.

49. Nwosu BU, Maranda L, Cullen K, Greenman L, Fleshman J, McShea N, Barton BA, Lee MM. A randomized, double-blind, placebo-controlled trial of adjunctive metformin therapy in overweight/obese youth with type 1 diabetes. PLoS ONE. 2015;10(9):e0137525. https://doi.org/10.1371/ journal.pone.0137525.

50. Nadeau K, Chow K, Alam L, Lindquist K, Cambell S, McFann K, Klingensmith G, Walravens P. Effects of low dose metformin in adolescents with type 1 diabetes mellitus: a randomized, double-blinded placebo-controlled study. Pediatr Diabetes. 2015;16(3):196-203. https://doi.org/10.1111/pedi. 12140.

51. Pandey AK, Gutch M, Mittal M, Kumar S, Razi SM. Can metformin be used in type 1 diabetes with insulin resistance: experience from tertiary care health center. J Assoc Physicians India. 2016;64(1):91.

52. Al Khalifah RA, Alnhdi A, Alghar H, Alanazi M, Florez ID. The effect of adding metformin to insulin therapy for type 1 diabetes mellitus children: a systematic review and meta-analysis. Pediatr Diabetes. 2017;. https://doi.org/10.1111/pedi.12493.

53. Konrad K, Datz N, Engelsberger I, Gurlich-Henn J, Hoertenhuber T, Knauth B, Meissner T, Wiegand S, Woelfle J, Holl RW. German/Austrian DPV Initiative. Current use of metformin in addition to insulin in pediatric patients with type 1 diabetes mellitus: an analysis based on a large diabetes registry in Germany and Austria. Pediatr Diabetes. 2015;16(7):529-37. https://doi.org/10.1111/pedi. 12203 Epub 2014 Aug 18.

54. Libman IM, Miller KM, DiMeglio LA, T1D Exchange Clinic Network Metformin RCT Study Group. Effect of metformin added to insulin on glycemic control among overweight/obese adolescents with type 1 diabetes: a randomized clinical trial. JAMA. 2015;314(21):2241-50. https://doi.org/10.1001/ jama.2015.16174.

55. Burchardt P, Zawada A, Tabaczewski P, Naskręt D, Kaczmarek J, Marcinkaniec J, Wierusz-Wysocka B, Wysocki H. Metformin added to intensive insulin therapy reduces plasma levels of glycated but not oxidized low-density lipoprotein in young patients with type 1 diabetes and obesity in comparison with insulin alone: a pilot study. Pol Arch Med Wewn. 2013;123(10):526-32 Epub 2013 Aug 8.

56. Lund SS, Tarnow L, Astrup AS, et al. Effect of adjunct metformin treatment on levels of plasma lipids in patients with type 1 diabetes. Diabetes Obes Metab. 2009;11(10):966-77.

57. Pitocco D, Zaccardi F, Tarzia P, et al. Metformin improves endothelial function in type 1 diabetic subjects: a pilot, placebo-controlled randomized study. Diabetes Obes Metab. 2013;15:427-31.

58. Ahmed FW, Rider R, Glanville M, Narayanan K, Razvi S, Weaver JU. Metformin improves circulating endothelial cells and endothelial progenitor cells in type 1 diabetes: MERIT study. Cardiovasc Diabetol. 2016;15:116. https://doi.org/10.1186/s12933-0160413-6.

59. Matsumoto K, Gera Y, Abe Y, Tominanga T, Yeki Y, Miyake S. Metformin attenuates progression of carotid arterial wall thickness in patients with type 2 diabetes. Diabetes Res Clin Pract. 2004;64:225-8.

60. Burchardt P, Zawada A, Kaczmarek J, et al. Association between adjunctive metformin therapy in young type 1 diabetes patients with excess body fat and reduction of carotid intima-media thickness. Pol Arch Med Wewn. 2016;126(7-8):514-20. https://doi.org/10.20452/pamw.3527.

61. Miller KM, Foster NC, Beck RW, et al. Current state of type 1 diabetes treatment in the U.S.: updated data from the T1D Exchange clinic registry. Diabetes Care. 2015;38:971-8.

62. Morris AD, Boyle DI, MacAlpine R, et al. The diabetes audit and research in Tayside Scotland (DARTS) study: electronic record linkage to create a diabetes register. DARTS/MEMO Collaboration. BMJ. 1997;315:524-8.

63. American Diabetes Association (2017) Standards ofmedical care in diabetes. Diabetes Care 2017; 40 (Suppl 1):S1-S135.

64. National Institute of Clinical Excellence (2016). Type 1 diabetes in adults: diagnosis and management of type 1 diabetes. Available from https:// www.nice.org.uk/guidance/ng17?unlid= 43059219201639184149. 